\title{
Ojo y visión: \\ un posible origen del entrecruzamiento en el quiasma óptico
}

\author{
Juan Diego Vélez ${ }^{1, *}$, Antonio Vélez ${ }^{2}$ \\ ${ }^{1}$ Escuela de Matemáticas, Universidad Nacional de Colombia, Medellín, Colombia \\ ${ }^{2}$ Departamento de Matemáticas, Universidad de Antioquia
}

\begin{abstract}
Resumen
A partir de una pequeña imagen plana que se proyecta sobre la retina de cada ojo, nuestro cerebro es capaz de reconstruir una realidad en tres dimensiones, una en la que los objetos del mundo físico se perciben en profundidad y cuyas posiciones se juzgan de manera extraordinariamente fiel, en coincidencia casi perfecta con las auténticas coordenadas espaciales. A partir de esos dos recuadros planos nuestro cerebro inventa un mundo visual, rico en detalles, matices y colores. Un proceso en apariencia tan simple requiere, no obstante, la contribución de una constelación de complejas y hasta ahora misteriosas rutinas cognitivas, algoritmos que la naturaleza ha descubierto en el transcurso de millones de año de evolución. En este artículo haremos un rápido y modesto recorrido a través de ese mundo extraordinario que es nuestro sistema visual. También propondremos una posible hipótesis para explicar el curioso y paradójico entrecruzamiento que ocurre en el quiasma óptico entre un hemisferio cerebral y el comando de su correspondiente área motriz contralateral.
\end{abstract}

Palabras clave: anatomía del ojo, quiasma óptico, evolución del ojo, ilusiones ópticas, Ley de Emmert, pareidolia.

Eye and vision: A possible origin of the crosslinking in the optic chiasm

\begin{abstract}
From a small flat image projected on the retina of each eye, our brain is able to reconstruct a three-dimensional reality, one in which the objects of the physical world are perceived in depth, and whose positions are judged faithfully, coinciding almost perfectly with their real space coordinates. From those two flat squared images, our brain invents a rich reality, full of details, colors and hues. A seemingly simple process requires, notwithstanding, the contribution of a constellation of complex, and so far, mysterious, cognitive routines, algorithms that nature has discovered over millions of years of evolution. In this article we will make a fast and modest journey through the extraordinary world of our visual system, and propose a plausible hypothesis that would explain the strange and paradoxical crossing at the midline optic chiasm.
\end{abstract}

Key words: Anatomy of the eye, optic chiasm, evolution of the eye, optical illusions, Emmert's Law, pareidolia.

\section{Introducción}

Dos pequeñas imágenes planas se proyectan sobre la retina de cada ojo. A partir de esos dos recuadros diminutos nuestro cerebro inventa un universo rico en detalles, matices y colores. El mundo del vidente y sus tres dimensiones, ese escenario largo, ancho y profundo en el cual nos movemos, es una de las más extraordinarias invenciones de nuestra mente.

No obstante, el acto de ver, un proceso en apariencia tan simple, requiere la contribución de una constelación de complejas y hasta ahora misteriosas rutinas cognitivas, sofisticados algoritmos que la naturaleza ha descubierto en el transcurso de millones de años de evolución.

En este artículo haremos un modesto y rápido recorrido a través de ese mundo maravilloso que es nuestro sistema visual. Para comenzar, mostraremos algunas de las hipótesis más aceptadas entre los biólogos para explicar cómo el simple mecanismo darwiniano de selección natural pudo haber “descubierto" las distintas soluciones al problema de la visión que hoy observamos en el mundo animal.

Por otro lado, especularemos acerca del caprichoso diseño del ojo humano, el cual se hace evidente en sus obvios "errores" de construcción, y propondremos una posible hipótesis para explicar el origen del curioso entrecruzamiento nervioso que ocurre en el quiasma óptico. Mostraremos, así mismo, cómo el acto de "ver” no es otra cosa que una compleja elaboración de nuestro aparato cognitivo, una cuya materia prima se limita a la escasa

\footnotetext{
*Correspondencia:

Juan Diego Vélez, jdvelez@unal.edu.co

Recibido: 21 de julio de 2015

Aceptado: 7 de septiembre de 2015
} 
información visual que llega a través de nuestros sentidos. Las complejidades de este mecanismo son manifiestas en las llamadas ilusiones visuales y en algunos fenómenos gestálticos, como en la pareidolia visual y en la llamada ley de Emmert (aquella ilusión en la que el Sol y la Luna parecen tener mayor tamaño cuando se encuentran cerca del horizonte), de la cual intentaremos dar una explicación.

\section{Evolución del ojo}

Desde los tiempos de Darwin el ojo ha sido por excelencia el arquetipo del órgano complejo. La pregunta ha intrigado por siempre a los biólogos: ¿cómo una cámara fotográfica en miniatura, dotada de obturador, lente ajustable y un fondo fotosensible (Figura 1) pudo haberse formado en el trascurso de la evolución de la vida en la Tierra? La pregunta mantuvo intrigado a Darwin, hasta el punto de manifestar que estaba dispuesto a abandonar su teoría si alguno de sus contradictores pudiese demostrarle que un órgano tan complejo como el ojo humano jamás podría aparecer mediante una sucesión de cambios graduales y que, por ende, escaparía al mecanismo de selección natural.

Hoy sabemos que la madre naturaleza no solo "descubrió" el ojo de la manera como Darwin había imaginado, sino que lo hizo muchas veces, de forma independiente, inventando multitud de soluciones diferentes. Muchas de las criaturas vivas que hoy conocemos poseen ojos harto similares a aquellos de animales ya extintos presentes en el registro fósil.

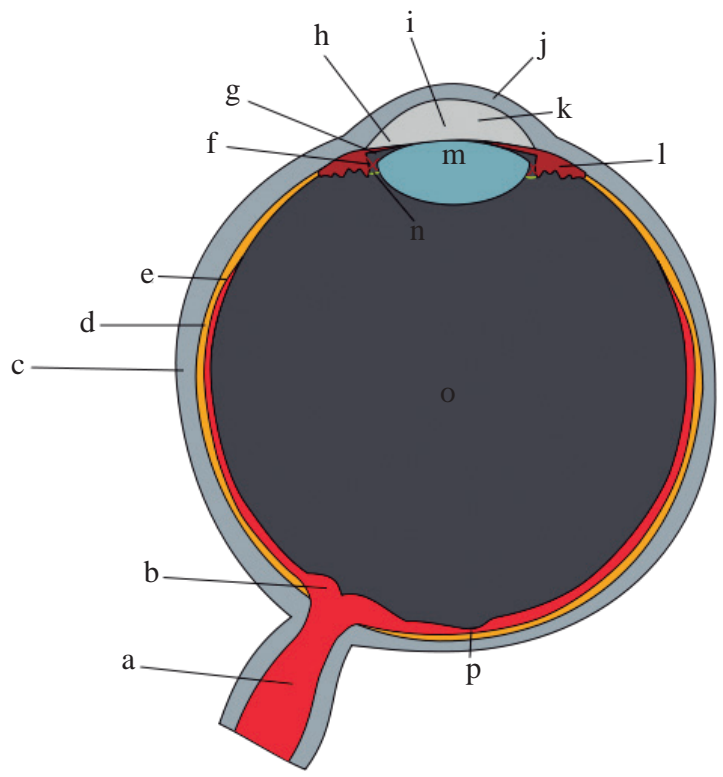

Figura 1. El ojo humano: una cámara fotográfica en miniatura. a: nervio óptico; b: disco óptico; c: esclerótica; d: coroide; e: retina; f: fibras sonulares; g: cámara posterior; h: iris; i: pupila; j: córnea; k: cámara anterior; l: músculo ciliar; m: cristalino; n: ligamento suspensorio; o: humor vítreo; p: fóvea.

Fuente: https://commons.wikimedia.org/wiki/File:Schematic_diagram_of_ the_human_eye.svg?uselang=es
Los ojos más simples en el mundo vivo aún se pueden observar en los unicelulares del género Euglena (Figura 2). Estos organismos poseen un pequeño punto fotosensible que determina la presencia o ausencia de luz. Y aunque inhabilitado para formar imágenes, el pequeño ojo logra poner en acción un diminuto flagelo, sistema locomotor del protozoario, capaz de dirigir al diminuto euglénido hacia las posibles fuentes de alimento.

En el comienzo el ojo pudo haberse limitado a una diminuta mancha fotosensible, la cual debió crecer pronto hasta alcanzar las dimensiones de un pequeño disco. Con el tiempo, una de las caras de este disco se cubrió de un fino sustrato de pigmento oscuro, lo que le permitió al ojo primigenio discriminar la dirección de la luz incidente, pues solo aquellos rayos que llegaban de manera frontal lograban activar la zona fotosensible. Es razonable conjeturar que los primeros pigmentos utilizados para llevar a cabo la fotosíntesis modificaron sus funciones hasta convertirse en sustancias químicas, como la rodopsina (presente en los bastones del ojo), capaces de reaccionar ante la presencia de luz.

El siguiente paso evolutivo consistió en la creación de una estructura invaginada en forma de copa. De esta manera, distintas partes de la superficie de la copa se iluminarían dependiendo del lugar del cual proviniera la luz, lo cual le dio aún más direccionalidad a esos ojos primitivos. Ojos en “forma de copa” todavía pueden apreciarse en los moluscos gasterópodos, y en algunos gusanos planos, en los que la invaginación representa una ventaja evolutiva, pues le permite al organismo determinar la ubicación de presas o depredadores dependiendo de la fuente de luminosidad y de las proyecciones de las distintas sombras (Figura 3).

Milenios más tarde, la abertura frontal, precursora del iris, debió cerrarse hasta convertir todo el conjunto en una especie de cámara oscura mediante la cual ya era posible distinguir siluetas. La abertura de esta cavidad oscura pudo haberse cubierto de un delgado recubrimiento epidérmico, una membrana transparente con alguna capacidad de refracción,

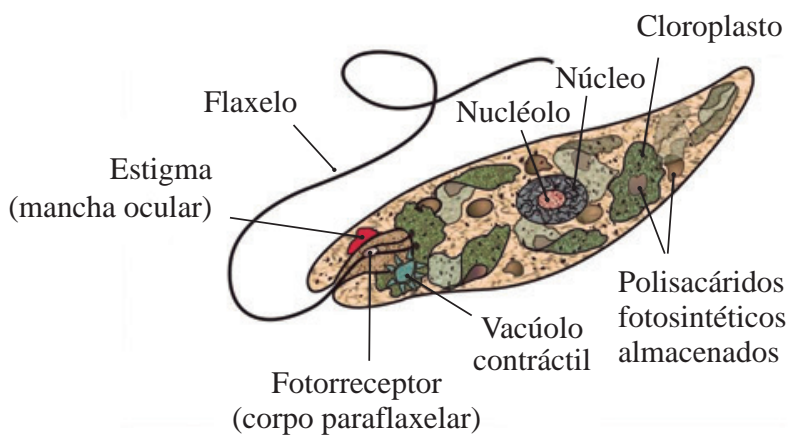

Figura 2. Euglena.

Fuente: https://commons.wikimedia.org/wiki/Category:Euglena\#/media/ File:Euglena_diagram_gl.jpg 


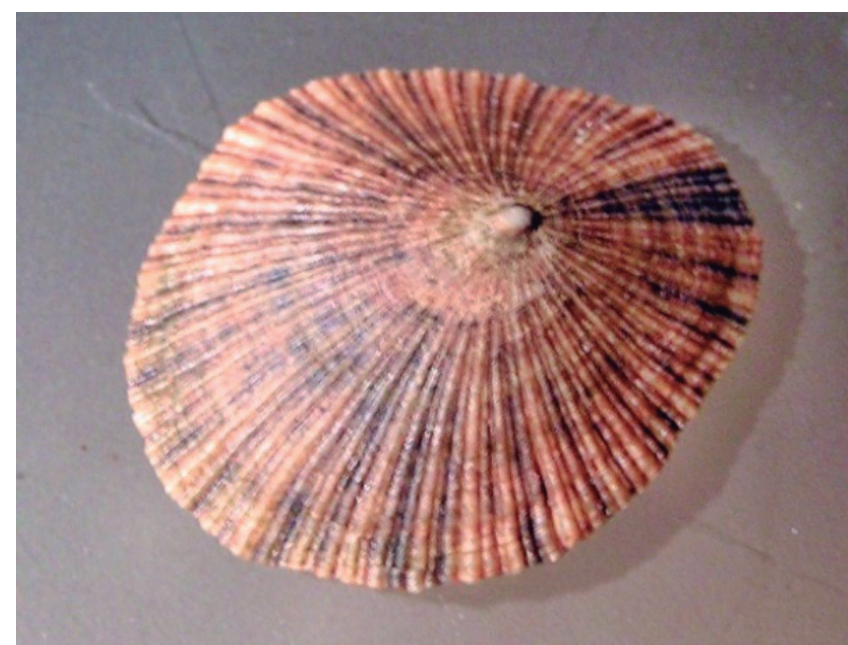

Figura 3. Patella, molusco gasterópodo. Fuente: https://commons. wikimedia.org/wiki/Category:Patella_(mollusc)?uselang=es\#/media/ File:Patella_variabilis_concolor_002.jpg

posible antecesora de la córnea y del cristalino. Existe multitud de criaturas vivientes "congeladas en el tiempo", las cuales poseen un sistema visual a mitad de camino que sugiere cómo pudo haber sido el desarrollo evolutivo de un órgano tan complejo como el ojo.

El nautilo, por ejemplo, está dotado de dos superficies fotosensibles que conforman una pequeña cámara oscura, sin córnea ni cristalino. En el anfioxo y en las estrellas de mar se puede observar un ojo más evolucionado: la misma cámara oscura se encuentra rellena con un material transparente y protegida por un delgado tramo de piel (Figura 4).

En los insectos, la evolución eligió una dirección diferente: en lugar de crear una cámara oscura, los ojos conservaron su tamaño pequeño. Con el tiempo, su forma se hizo alargada, estrecha y profunda. Estos ojos en forma de cuña se multiplicaron en número y se empaquetaron formando esferas. Cada uno de esos ojos diminutos debió permanecer aislado de sus vecinos mediante un pigmento oscuro depositado en las paredes laterales. Fue así, quizá, como aparecieron los extraordinarios ojos compuestos de los insectos (Figuras 5 y 6), otra solución ingeniosa de la madre naturaleza al problema de construir un órgano de la visión.

Existen así mismo en el reino animal soluciones ópticas de "alta tecnología” al problema de recoger luz: en lugar de lentes, la naturaleza descubrió, al igual que los humanos, la forma de utilizar espejos: el ojo del crustáceo ostrácodo Gigantocypris no consiste en una lente sino en un espejo parabólico que recibe la luz y la enfoca en una diminuta retina esférica situada en el foco del paraboloide.

Y si de construir fotorreceptores ultrasensibles se trata, algunos animales nocturnos poseen detrás de la retina una capa de células reflectoras, el tapetum lucidum, que les permite a los rayos incidentes reflejarse y excitar por

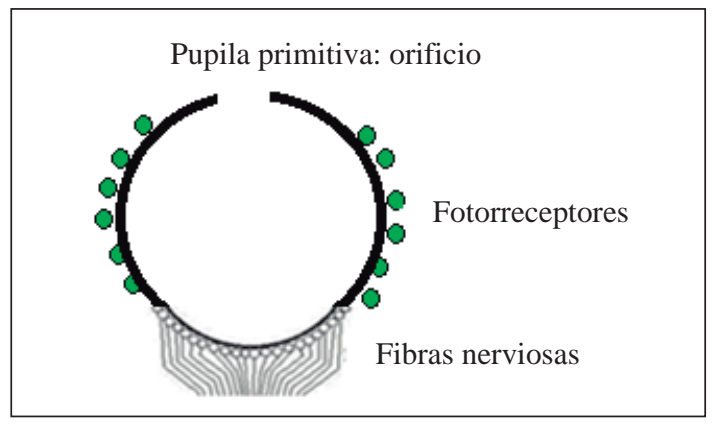

Figura 4. Ojo del nautilo. Ilustración de los autores.

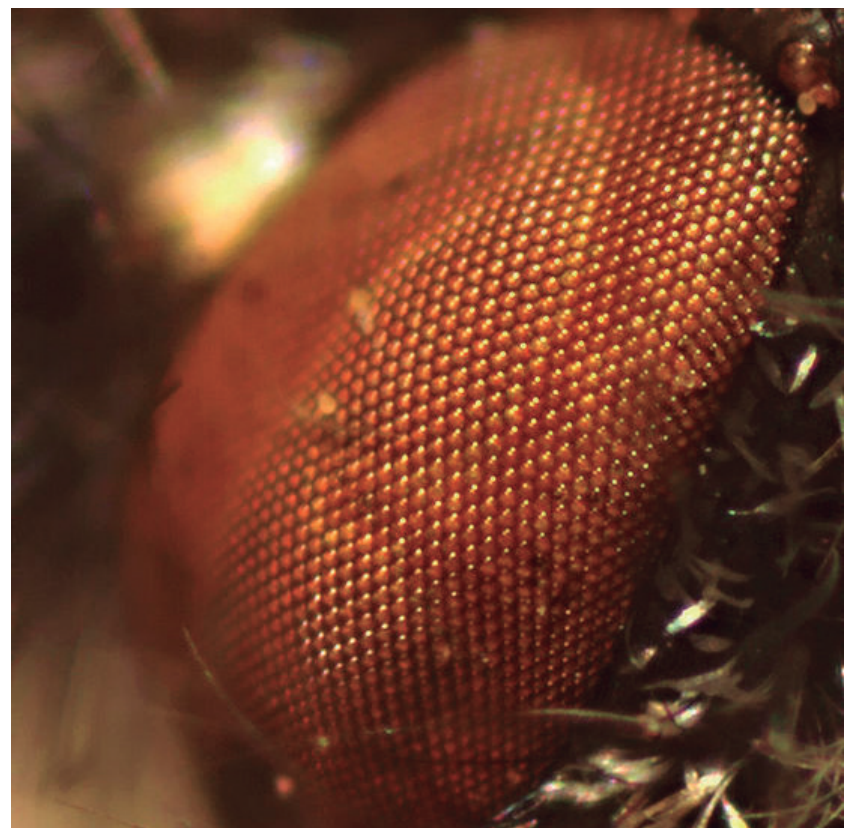

Figura 5. Ojo compuesto. Fuente: https://commons.wikimedia.org/ wiki/File:Bombylidae_ojo_compuesto.jpg?uselang=es

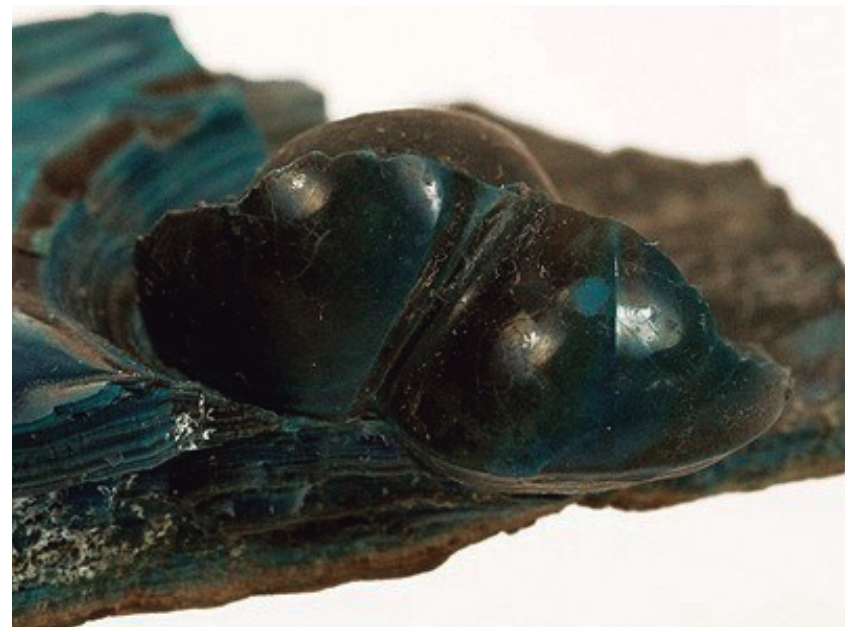

Figura 6. Ojos fósiles de trilobites de hace millones de años. Fuente: https://commons.wikimedia.org/wiki/File:Azurite-216054.jpg?uselang=es 
segunda vez la retina, lo cual duplica su sensibilidad. Esto explica por qué cuando en la noche los faros de un carro iluminan los ojos de los perros y los gatos, y del ganado, estos parecen brillar como dos diabólicos círculos brillantes (Figura 7) (Vélez, 1998).

\section{¿Diseño inteligente?}

Si los órganos de nuestros cuerpos hubiesen sido pensados por un diseñador inteligente, nuestros ojos, como los de todos los mamíferos, no poseerían tan obvios errores de construcción. En los cefalópodos, por ejemplo, los vasos sanguíneos de la retina y los ramales nerviosos que de allí se desprenden están dispuestos, como cualquier ingeniero competente lo hubiera hecho, por debajo de ella, de tal forma que no interfieran con la luz incidente. En los mamíferos, por el contrario, los vasos sanguíneos y el nervio óptico se encuentran por encima de la retina, y le roban luz. Hasta 90 \% de la luz incidente se pierde al atravesar la córnea, el humor acuoso, el cristalino, el humor vítreo, más todo el entramado nervioso y vascular. Si el ojo no hubiese sido el resultado del ensayo y el error de un «relojero ciego», hoy podríamos leer bajo el claro de luna y caminar sin tropiezos durante la noche (Vélez \& Álvarez, 2014).

Existe otro defecto en el diseño del cristalino de los mamíferos, uno que viene a manifestarse en la edad madura: la presbicia. Con el paso de los años, el cristalino se va engrosando a medida que se acumulan capas de tejido nuevo, lo cual disminuye su elasticidad. El resultado de estos cambios es la pérdida de acomodación, un problema que curiosamente no ocurre con los peces ni con los cefalópodos. Tampoco sufren de presbicia ni las aves ni las lagartijas ni las tortugas, como si el Creador se hubiese esmerado en diseñar buenos ojos entre las criaturas "inferiores", y hubiese sido algo torpe a la hora de perfilar los ojos de su creación suprema.

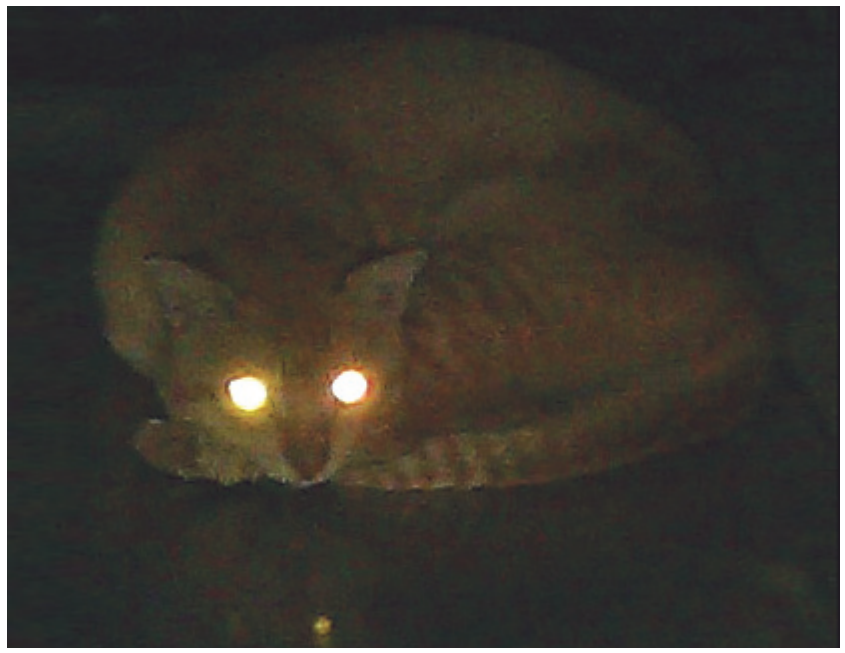

Figura 7.Tapetum lucidum. Fuente: https://commons.wikimedia.org/ wiki/FileCat\%27s_eyes_glowing_in_the_dark.jpg? uselang=es
Y existen aún más errores de diseño, como la presencia de un punto ciego, un lugar en nuestros ojos carente de receptores lumínicos (Figura 8). Podemos realizar el siguiente experimento para demostrar la existencia de este punto ciego: dibujemos en una hoja de papel una estrella y un pequeño círculo, separados entre sí unos veinte centímetros. Coloquemos ahora la hoja a unos cuarenta centímetros de distancia, y mientras cerramos el ojo derecho, fijamos la mirada con el izquierdo en la pequeña estrella. Luego vamos acercando lentamente el papel: se podrá observar cómo el círculo desaparece, precisamente cuando este entra en el área sin sensibilidad óptica. Al acercar un poco más el papel, el punto vuelve a aparecer (Figura 9).

\section{El cerebro: prolongación del ojo}

Algunos biólogos conjeturan que el cerebro bien pudo haber aparecido a manera de extensión o apéndice del ojo. De hecho, nuestras retinas están conformadas por neuronas modificadas. Es factible que en los comienzos de la vida el primer cerebro rudimentario no cumpliera otra función que activar el sistema locomotor, una vez se lograra excitar los órganos fotosensibles. Este primer paso evolutivo se puede considerar como un esbozo inicial de conducta inteligente: buscar el alimento en aquel lugar de donde proviene la luz, es decir, la superficie del océano,

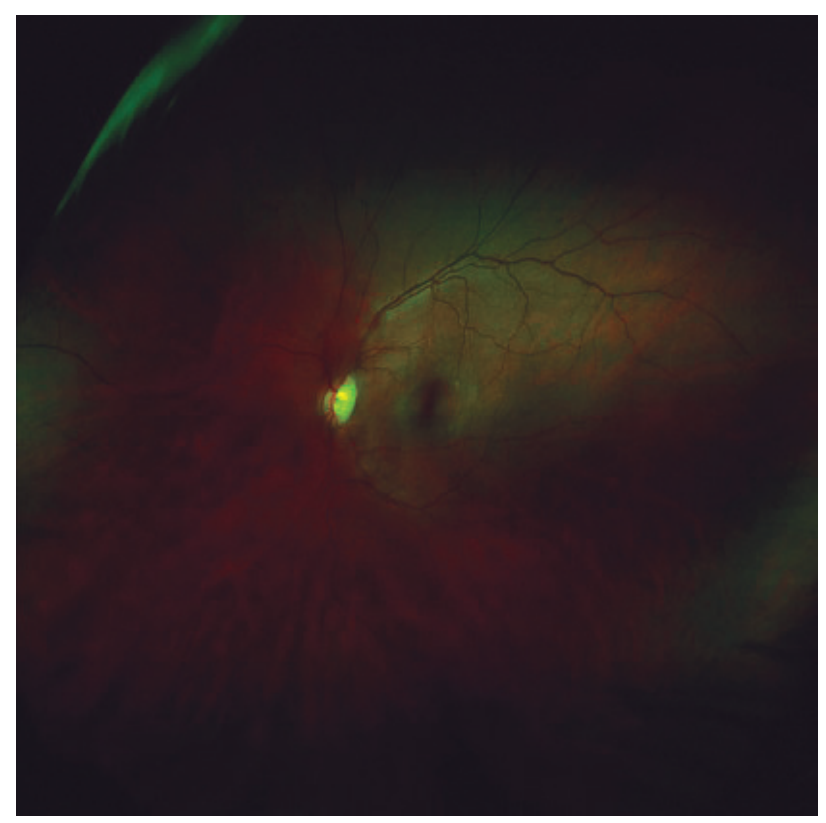

Figura 8. Punto ciego. Fuente: https://commons.wikimedia.org/wiki/ File:Left_Retina.jpg?uselang=es

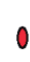

0

Figura 9. Punto ciego (experimento). Ilustración de los autores. 
donde suele ser más abundante. Asimismo, pudo ser la primera manifestación de una "decisión voluntaria" en la historia de la vida.

El caprichoso entrecruzamiento de los nervios ópticos en el quiasma (Figura 10) bien podría tener un origen que revelara la manera cómo el cerebro apareció, justamente para interpretar la información visual. Según una hipótesis conjunta desarrollada por los autores, una posible explicación evolutiva sería la siguiente: si pensamos en un organismo primitivo como una especie de «triciclo fototáxico» (Figura 11), la fotocelda de la izquierda, más cercana a la fuente lumínica y mejor orientada con respecto a ella, captaría más energía que su compañera y, en consecuencia, enviará una señal más intensa a la aleta del lado opuesto. Esta aumentaría así su velocidad de remo, lo cual haría que el vehículo girara un poco hacia la izquierda. En esta posición el animal estaría preparado para iniciar su rumbo hacia la fuente energética (trayectoria punteada). Otras explicaciones han sido pro-puestas por diferentes autores (Vulliemoz, et al., 2005).

\section{Vemos con nuestros cerebros}

Podemos afirmar, aunque nos parezca poco intuitivo, que no vemos con nuestros ojos sino con nuestro cerebro. Macacos y chimpancés privados de todo estimulo visual durante los primeros meses de vida jamás "aprenden a ver”, y permanecen ciegos de por vida, a pesar de que sus ojos se encuentren sanos y perfectamente desarrollados. Cuando se examina al microscopio la corteza cerebral de los animales privados de todo estímulo visual, se observa una deficiente interconexión sináptica, de donde se infiere que los circuitos visuales encargados de procesar la información proveniente de los ojos se desarrollan tempranamente con la experiencia de "ver", un evento que debe ocurrir cuando todavía el cerebro se encuentra en formación (Vélez, 2007).

En la literatura médica se relata el triste caso de un hombre que perdió la vista a los diez meses de edad debido a un trauma en la córnea. Sidney Bradford creció ciego y aprendió a vivir su vida como cualquier otra persona con esa discapacidad. Sin embargo, los avances de la medicina, específicamente los trasplantes de córnea, trajeron por fin una luz de esperanza y la promesa de poder recuperar su visión. Pero ello ocurrió cuando Bradford ya contaba con 52 años de edad. La expectativa de la operación dejó al mundo en vilo ¡Cuán maravilloso sería el testimonio de aquel hombre una vez abriera sus ojos y se encontrara con la infinita riqueza del mundo visual!

Pero después de la operación los progresos del señor Bradford fueron desalentadores: jamás pudo cruzar la calle con los ojos abiertos. El mundo era para él un inmenso caleidoscopio ininteligible de colores en movimiento, de siluetas amenazantes que se le venían encima. Los rostros de las personas le resultaban incomprensibles pues carecían

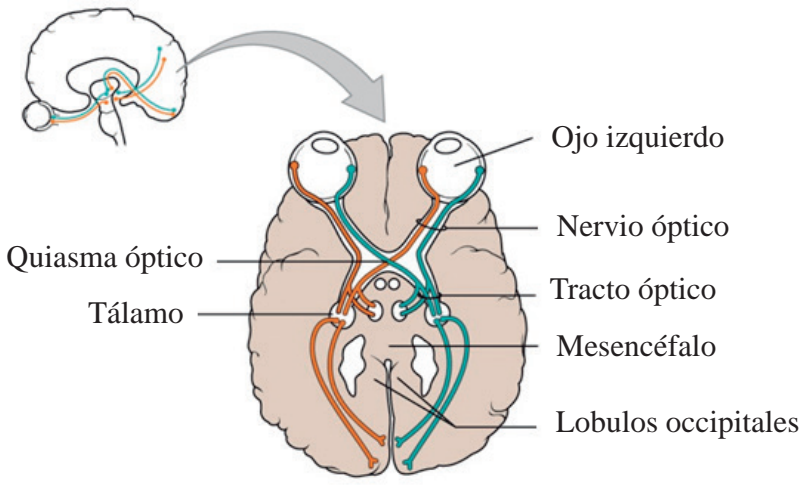

Figura 10. Interconexión invertida en el quiasma óptico Fuente: https://commons.wikimedia.org/wiki/File:1204_Optic_Nerve_vs_ Optic_Tract.jpg y https://commons.wikimedia.org/wiki/Category:Optic_ chiasm\#/media/File:1204_Optic_Nerve_vs_Optic_Tract.jpg

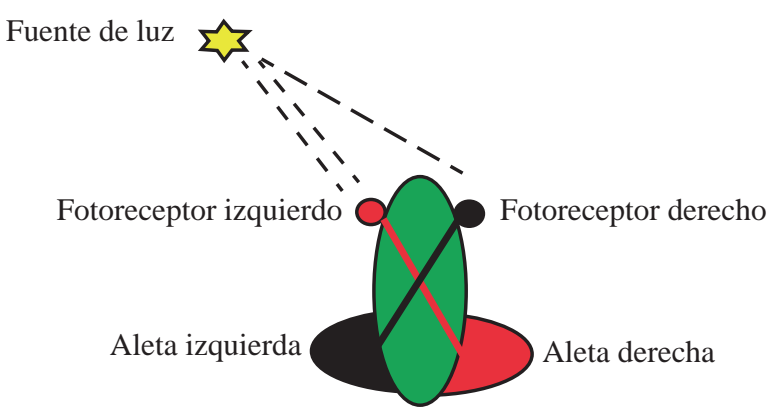

Figura 11. Triciclo fototáxico. Ilustración de los autores.

de detalles y expresión. Las mujeres, antes hermosas --se quejaba el señor Bradford--, ahora le resultaban insoportablemente feas (Ackroyd, et al., 1974).

El hecho cruel es que nunca aprendió a ver. Creía, por ejemplo, que podía salir de su casa, no como siempre lo hizo, por la puerta principal, sino descolgándose hasta la calle por la ventana de su alcoba, jsituada en un cuarto piso! Para su cerebro, la simple tarea de calcular la profundidad y las distancias del mundo real escapaba a sus capacidades. Desde el balcón de su residencia, la calle parecía estar justo al alcance de sus pies.

El caso de Bradford se ha repetido más de una vez. Algunos bebés nacen con cataratas en ambos ojos, defecto que los convierte en ciegos de nacimiento. Durante mucho tiempo se creyó que no era conveniente operarlos hasta alcanzar los diez años de edad. Hay que recordar, eran épocas en las que la cirugía implicaba riesgos muy altos. Pero muy pronto se dieron cuenta de que los niños operados a tan tardía edad quedaban limitados de por vida, casi ciegos. Nunca fueron capaces de estimar las distancias, ni de reconocer patrones, ni formas. En síntesis, una vez pasado el periodo de plasticidad cerebral, los niños quedaban incapacitados para ver, tarea que a todos nos resulta tan cotidiana, tan normal y tan sencilla como respirar. 


\section{Psicología de la percepción visual}

Las ilusiones visuales constituyen una prueba indirecta de que no todo lo que vemos está allí, en el mundo físico, pues estas resultan de la interpretación que nuestro cerebro hace de la información que llega a través de nuestros sentidos. Podemos realizar experimentos muy simples que nos permiten llegar a esta conclusión. Por ejemplo, ¿por qué al mover la mirada de un lado a otro el campo visual permanece fijo, no obstante que desde el punto de vista óptico este debería moverse, pues la imagen en cada retina se desplaza en sentido contrario al movimiento de nuestros ojos? Por otro lado, si presionamos levemente con un dedo uno cualquiera de nuestros ojos, observamos que en efecto la imagen sí se mueve, como sería natural conjeturar.

La razón de dicha paradoja estriba en que en el primer caso los movimientos oculares son controlados por los seis pares de músculos encargados de la rotación, la elevación y la depresión de los globos oculares. Cuando ello ocurre, nuestro cerebro «da la orden» de contrarrestar el inevitable desplazamiento aparente del campo visual, lo que no sucede cuando el movimiento del globo ocular se debe a un agente externo, como el dedo, y no está asociado al comando voluntario de «mover la mirada» (Figura 12).

\section{Triángulo de Kanizsa}

Una prueba fehaciente de que podemos ver objetos que no se encuentran en el mundo real la proporciona el llamado triángulo de Kanizsa, un contorno subjetivo construido enteramente por nuestro cerebro. En la Figura 13 se puede apreciar un triángulo blanco ilusorio que, de hecho, aparece más brillante que el área circundante, aunque la luz de fondo sea igual.

\section{Ley de Emmert}

El fenómeno conocido como ley de Emmert es una ilusión visual bien conocida, responsable de que veamos el Sol y la Luna de tamaños mucho más grandes cuando estos astros se encuentran cerca del horizonte. Al contrario, cuando miramos la ciudad a través de la ventanilla de un avión a baja altura tenemos la impresión de estar viendo un mundo de dimensiones minúsculas, uno en el cual las casas y los carros parecen de juguete.

El fenómeno puede explicarse en términos matemáticos de la siguiente manera: el tamaño aparente de un objeto, t, aquel que determina nuestro cerebro, es aproximadamente la distancia aparente, $\mathrm{d}$ (resultado de un complejo estimativo que realiza nuestro aparato cognitivo), multiplicada por el ángulo subtendido por dicho objeto (en radianes). Simbólicamente, $t \simeq a d$. La ley es una buena aproximación de la ecuación $t=d \tan (a)$, ya que $\tan (a) \simeq a$, para valores pequeños del ángulo $a$ (Figura 14).

La ley de Emmert explicaría la ilusión antes mencionada (Figura 15). Ocurre en ese caso que nuestro cerebro estima de manera diferente la distancia aparente del astro cuando

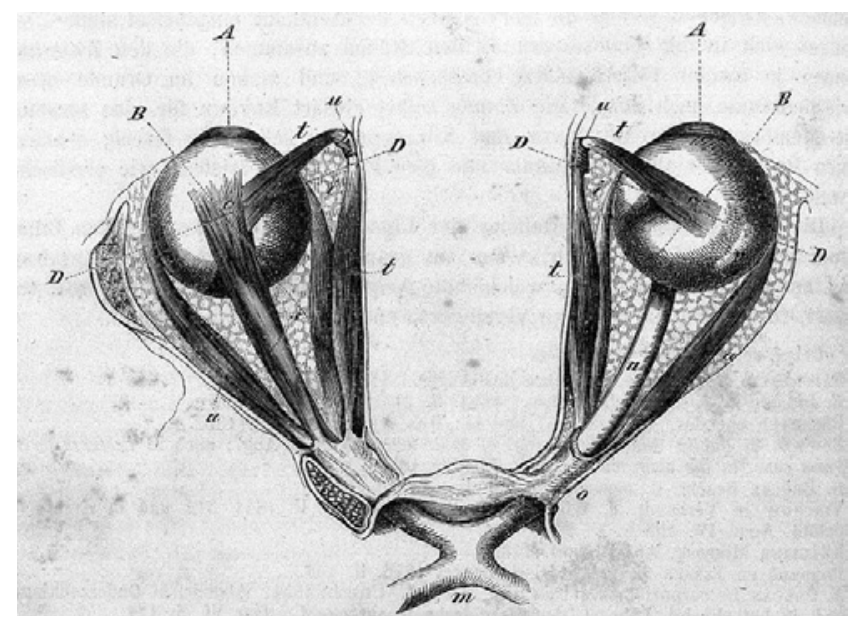

Figura 12. Músculos oculares.

Fuente: https://commons.wikimedia.org/wiki/File:Optic_nerve_and_ocular_ muscles._Wellcome_L0009855.jpg?uselang=es

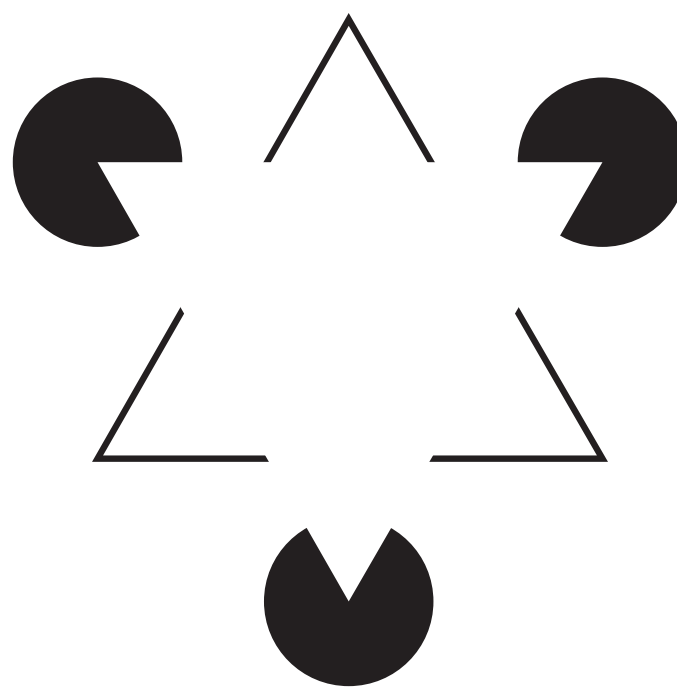

Figura 13. Triángulo de Kanizsa.

Fuente: https://commons.wikimedia.org/wiki/File:Kanizsa_triangle.svg

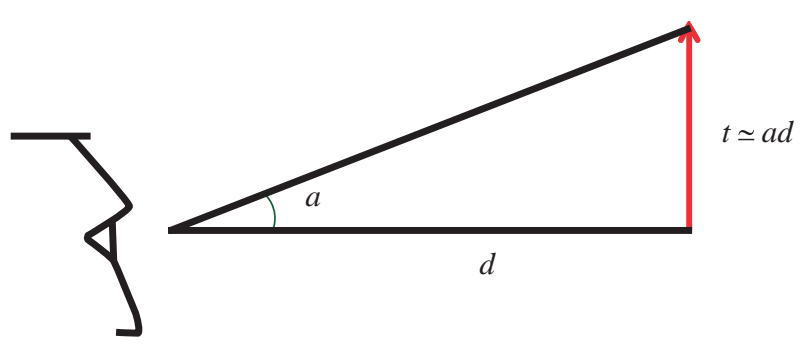

Figura 14. Ley de Emmert. Ilustración de los autores.

este se encuentra cerca del horizonte y cuando se halla en el cenit. En el plano del horizonte contamos con multitud de puntos de referencia, mientras que en el cenit todo parece estar situado a igual distancia (por ello la ilusión de que 
el cielo es una gran bóveda). De allí que al amanecer o al atardecer el Sol o la Luna parezcan estar mucho más lejos, pues nuestro cerebro nos indica, para dar un ejemplo, que el Sol estaría situado detrás de todos los postes de luz, más allá de la casas que se divisan en la distancia, incluso más lejos que la montaña que se aprecia en el horizonte, e incluso más allá de las nubes. Si llamamos D a la distancia estimada por nuestro cerebro cuando el Sol se ve en el horizonte, y d, a aquella cuando el astro se encuentra en el cenit, lo anterior se puede resumir en la desigualdad $\mathrm{D}>\mathrm{d}$. De otro lado, el ángulo a subtendido por el astro es el mismo en ambos casos, pues dicho ángulo solo depende de su diámetro real y de su distancia verdadera. Así, según la ley de Emmert, los tamaños aparentes serían en cada caso $\mathrm{T}=\mathrm{Da}$ y $\mathrm{t}=\mathrm{da}$. Pero $\mathrm{D}>\mathrm{d}$ implica $\mathrm{T}>\mathrm{t}$ (Figura 16).

Algunos han argumentado que el mayor tamaño aparente en el horizonte se debe a un efecto de lente de la atmósfera. La teoría puede refutarse sin dificultad: basta tomar una

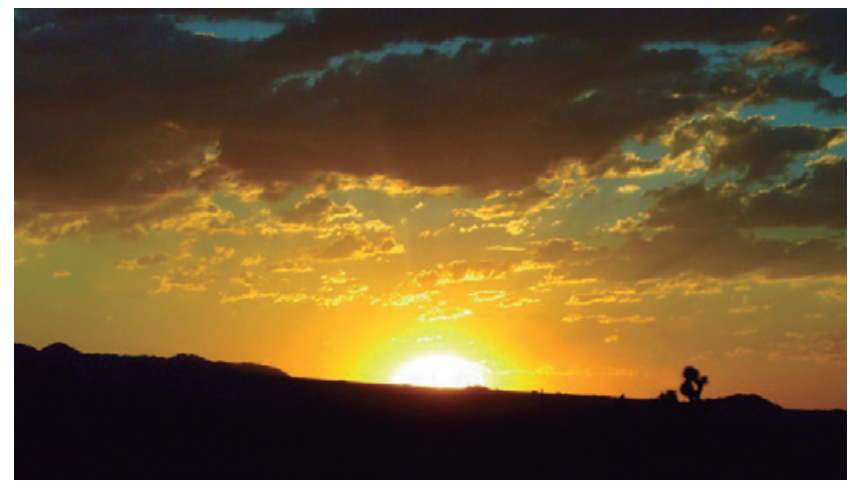

Figura 15. Ley de Emmert y tamaño aparente del Sol cerca del horizonte. Fuente: https://commons.wikimedia.org/wiki/Sun\#/media/File: Actual_Sunset.jpg

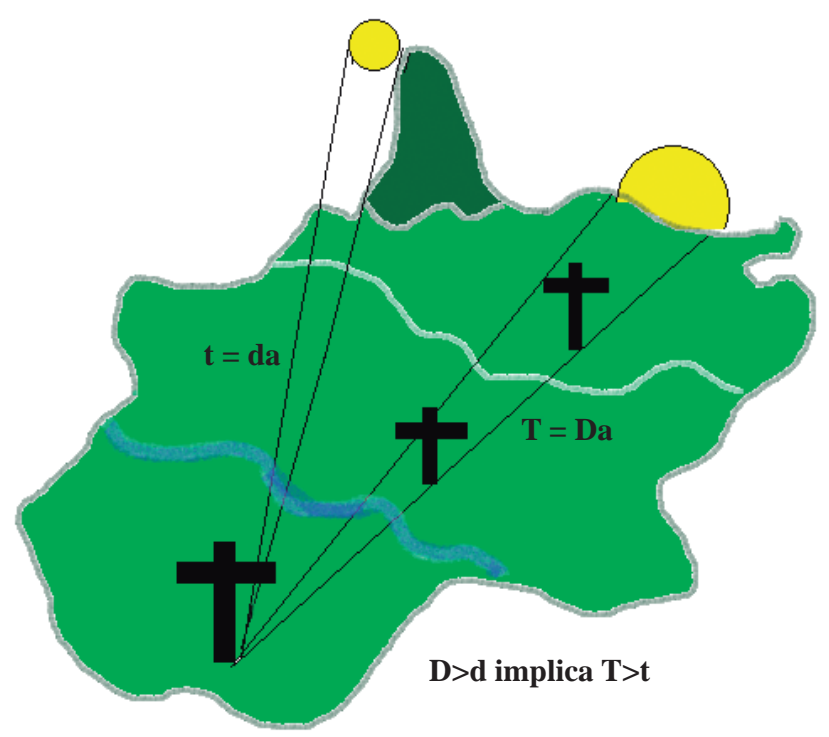

Figura 16. Ley de Emmert (Diagrama). Ilustración de los autores.

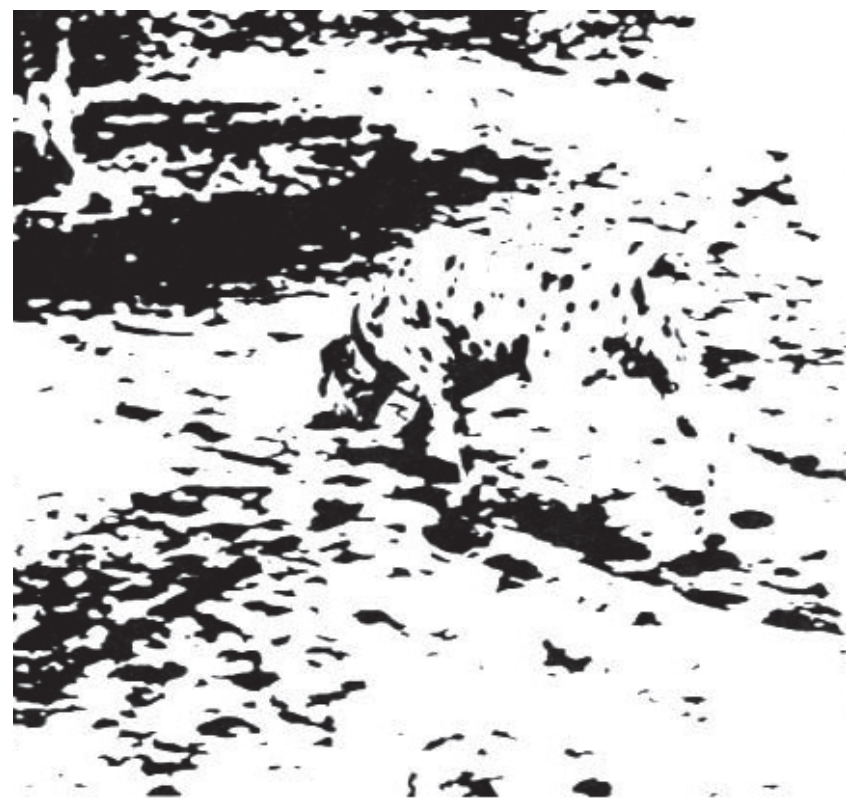

Figura 17. El dálmata "escondido".

Fuente: https://commons.wikimedia.org/wiki/Category:Gestalt?uselang=es\#/ media/File:Gestalt5.PNG

serie de fotografías del Sol o de la Luna en su movimiento por la bóveda celeste para comprobar que los diámetros permanecen constantes a lo largo de todo el recorrido.

\section{Reconocimiento de patrones}

Una de las características más extraordinarias de nuestro sistema visual puede ser su capacidad para distinguir y reconocer patrones. Podemos adivinar, por ejemplo, la silueta de un perro dálmata en las manchas caóticas de la siguiente fotografía (Figura 17).

Nuestra capacidad para reconocer patrones depende de rutinas que podríamos denominar gestálticas (reconocimiento por contexto), como puede demostrarse en el hecho de que casi toda persona es capaz de leer sin la menor dificultad el siguiente texto en el que solo es reconocible la estructura global, mientras que la información local es errónea.

C13R70 D14 D3 V3R4N0 3574B4 3N L4PL4Y4 0853RV4ND0 4 D05 CH1C45 8R1NC4ND0 3N 14 4R3N4. 357484N 7R484J484ND0 9UCH0 C0N57RUY3ND0 UN C4571LL0 D3 4R3N4 C0N 70RR35, P454D1Z05 0CUL705 Y PU3N735. CU4ND0 357484N 4C484ND0 V1N0 UN4 0L4 D357RUY3ND0 70D0.

"Cierto día de verano estaba en la playa observando a dos chicas brincando en la arena. Estaban trabajando mucho construyendo un castillo de arena con torres, pasadizos ocultos y puentes. Cuando estaban acabando vino una ola destruyendo todo" (Vélez, et al., 2010).

Y podemos reconocer multitud de "patrones escondidos", como se ve en las siguientes imágenes (Figuras 18 y 19): 


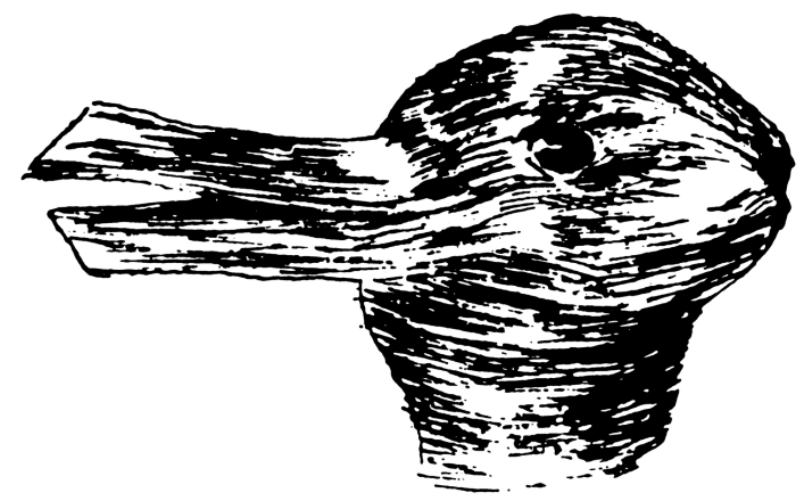

Figura 18. ¿Pato o conejo? Fuente: https://commons.wikimedia.org/ wiki/Category:Pareidolias_in_art\#/media/File:Duck-Rabbit.png

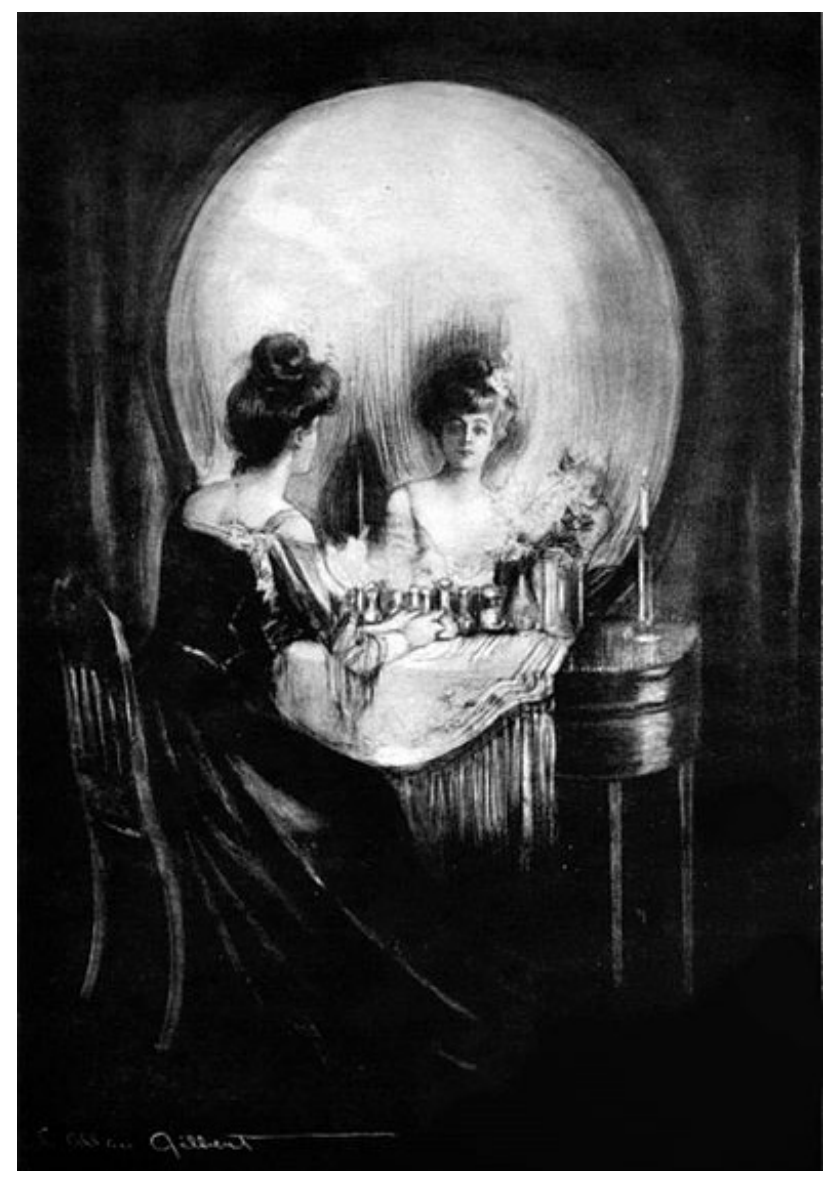

Figura 19. ¿Una calavera?

Fuente: https://commons.wikimedia.org/wiki/File:Allisvanity.jpg

\section{Pareidolia}

Algunos recordarán las fotografías de Sidonia, esa región de la superficie de Marte donde se encuentra una formación rocosa que recuerda el rostro de un antiguo faraón mirando hacia el cielo. Más de un ufólogo encontró en la cara marciana (Figura 20) la confirmación de que la NASA ocultaba información sobre la existencia de civilizaciones

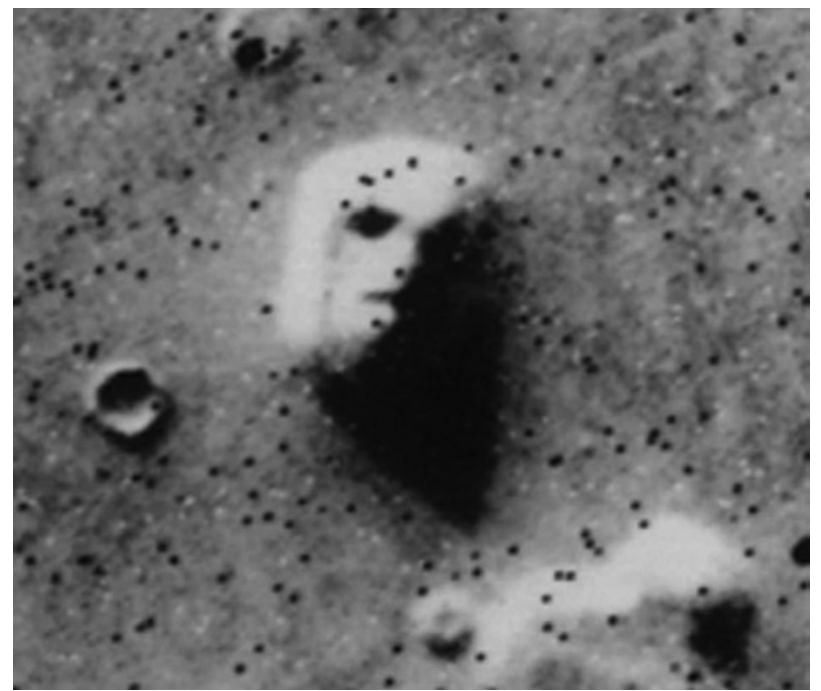

Figura 20. La cara marciana.

Fuente: https://commons.wikimedia.org/wiki/File:Martian_face_viking_ cropped.jpg?uselang=es

extraterrestres. Tras años de discusiones, el alegato 'conspiranoico' finalmente se desmoronó: en 2001, la nave Mars Global Surveyor volvió a fotografiar la misma zona, esta vez a una distancia de escasos 400 kilómetros. Visto de cerca, el inconfundible rostro humanoide resultó ser una meseta rocosa salpicada de picos y depresiones, situada en medio del yermo y polvoriento paisaje marciano (Ziegler, 2013).

Pareidolia es un vocablo que se deriva de la palabra griega eidolon, que quiere decir figura, y del prefijo para, que significa junto. También es el término que utilizan los psicólogos para designar esas ilusiones de la percepción en las que rostros humanos o formas animales parecen dibujarse en las nubes, en los nudos de la madera, en las humedades de un muro o en las salientes y grietas de una roca. El fenómeno aparece como respuesta automática de nuestro aparato cognitivo cuando la información sensorial es ambigua o insuficiente.

Nuestro cerebro, a la caza permanente de relaciones, trata de completar la información ausente asimilándola a patrones familiares. De ahí que los nudos en el tronco de un árbol se transfiguren de súbito en el perfil de un hombre narigudo o en la figura de una bruja, y los faros y la parrilla de un vehículo, en una cara humana. Quizás ello también explique por qué la Santísima Virgen escoge hacer sus apariciones en objetos tan impíos como las humedades de un muro derruido, los chamuscados de una tortilla o la corteza de un buñuelo (Ziegler, 2013).

A continuación se pueden apreciar un par de ejemplos de pareidolia (Figuras 21 y 22).

Estamos especialmente dotados para reconocer una clase de patrón particularmente importante para nuestra supervivencia: el rostro humano. De allí que existan regiones del córtex 


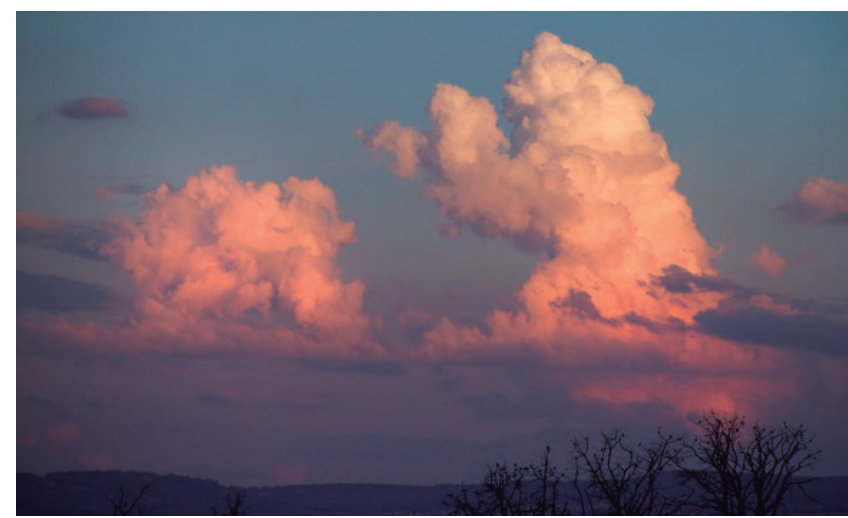

Figura 21. Rostros y formas animales en las nubes.

Fuente: https://commons.wikimedia.org/wiki/Category:Pareidolias\#/media/ File:SharkOrSubmarine4024617900.jpg

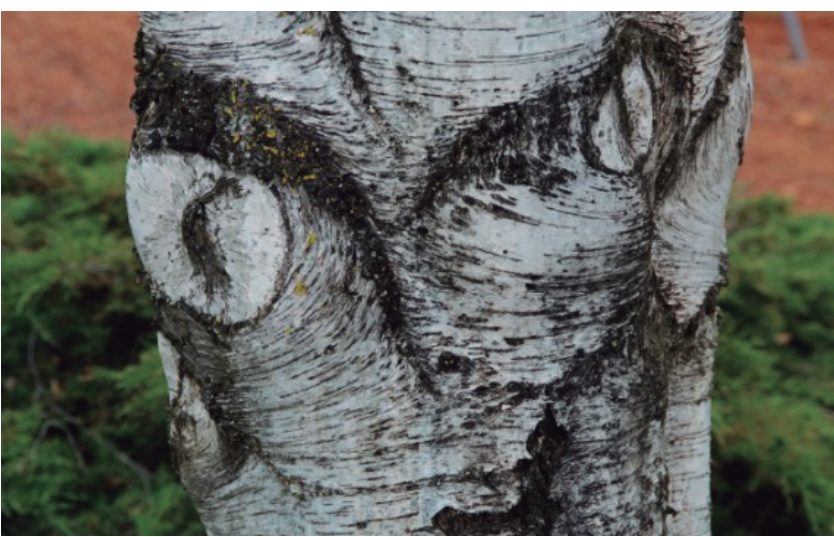

Figura 22. Ojos y caras donde en realidad no hay ninguna.

Fuente: https://commons.wikimedia.org/wiki/Category:Pareidolias\#/media/ File:N\%C3\%A9cropole_nationale_de_Sigolsheim_2013_51.jpg

visual especializadas exclusivamente en el reconocimiento de caras. Una cara vista en una posición anormal puede tener defectos que pasarían desapercibidos, pero que serían clarísimos si se nos presenta en su posición normal.

Existe, de hecho, una forma específica de agnosia visual (anormalidad para procesar información visual), caracterizada por la incapacidad de reconocer rostros, pues aunque se distingan cada uno de los rasgos de una cara: boca, nariz, ojos, cejas..., no es posible recordar su ubicación dentro de la cara. Quienes padecen esta enfermedad, llamada prosopagnosia, pueden recordar los rostros de sus amigos y familiares, incluso recuerdan el cabello, los tonos de la piel, todo lo que en general se denomina contexto de la persona. No obstante, no pueden reconocer o comprender el rostro de las personas que ven (Sacks, 1987).

\section{El misterio de las ilusiones ópticas}

Aunque la neurología moderna ha comenzado a comprender cómo funciona ese complejo sistema ojo-cerebro, muchas de las ilusiones ópticas más conocidas carecen aún de una explicación satisfactoria. No obstante, algunas ilusiones visuales han sido bien explicadas, como ocurre con el cubo de Necker (Figura 23), el cual parece cambiar de posición relativa cuando se fija la mirada en él durante algún tiempo.

En este caso, la ilusión se produce por la ambigüedad inherente a la figura, pues sin más ayuda que la información visual disponible, el punto negro podría, por ejemplo, estar situado en la esquina superior derecha de la cara izquierda o bien podría estar en el centro de la cara posterior. Ambas hipótesis son consistentes con la información visual presente, y es por ello que nuestro cerebro propone inicialmente una de las soluciones, y luego, independientemente de nuestra voluntad, descubre otras soluciones posibles, las cuales se manifiestan como cambios súbitos en la posición espacial del cubo.

Pero no todas las ilusiones ópticas han sido bien comprendidas. En la llamada ilusión de Herman, pequeños puntos grises fugaces se ven en las intersecciones de la figura siguiente (Figura 24).

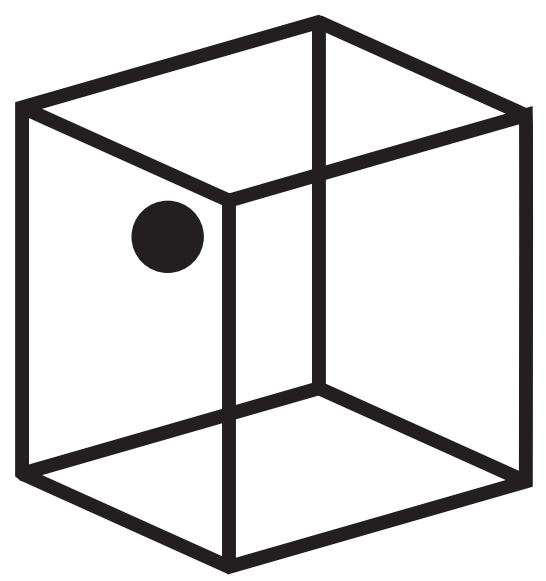

Figura 23. Cubo de Necker. Ilustración de los autores.

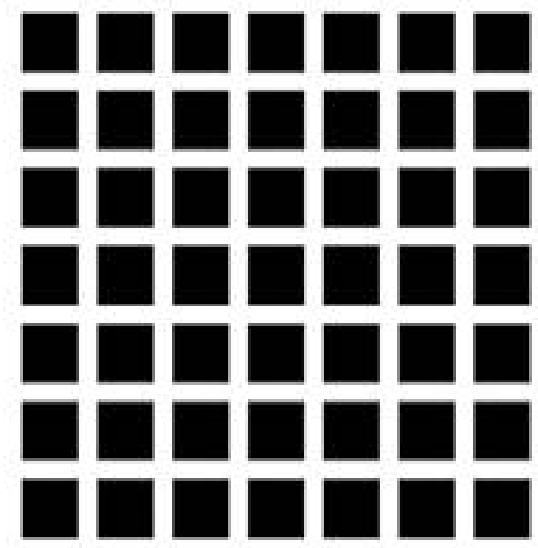

Figura 24. Ilusión de Hermann.

Fuente: https://commons.wikimedia.org/wiki/File:Grid_illusion.svg 
El fenómeno se ha explicado como el resultado de la competición e inhibición de los distintos receptores que se encuentran en la retina. Existen en la retina dos tipos de fotorreceptores que se activan, unos en la presencia de luz y otros en su ausencia. Estos conjuntos de receptores lumínicos "disparan" conjuntamente a una única célula ganglionar, la cual transmite la información final al nervio óptico. A los campos se les denomina on center y off center, dependiendo de si el receptor que se encuentra en la región del centro se activa con la presencia de luz.

Cuando la luz es percibida por ambos tipos de centros, estos compiten entre sí. A esta interacción competitiva se la llama inhibición lateral, responsable de la aparición de las pequeñas manchas grises: la ilusión ocurriría cuando algunos de los receptores de oscuridad que se encuentran rodeando el centro se disparan con el impulso lumínico mientras que otros no lo hacen. Esto causaría una reacción inhibitoria, ya que la luz que detecta la porción oscura del campo reduce la actividad receptiva total del campo. Pero como hay más fotorreceptores de oscuridad, estos contrarrestarían las señales de los fotorreceptores de luz, lo cual hace que las áreas de intersección se vean pobladas por puntos grises.

\section{Conclusiones}

A medida que avanzan la neurología y las ciencias de la computación aumenta nuestra comprensión sobre la manera en que funciona el complejo sistema ojo-cerebro.
Sin embargo, la más inmediata y natural de las rutinas cognitivas, la visión, todavía permanece, en su mayor parte, en el más absoluto misterio.

\section{Conflicto de intereses}

Los autores declaran que no tienen conflicto de intereses.

\section{Bibliografía}

Ackroyd, C., Humphrey, N. K., Warrington, E. K. (1974). Lasting effects of early blindness a case study. The Quarterly Journal of Experimental Psychology, 26 (1): 114-124.

Sacks, O. (1987). El hombre que confundió a su mujer con un sombrero. Barcelona. Muchnik editores. p. 275.

Vélez, A. (1998). Del Big Bang al Homo sapiens. Medellín. Editorial Universidad de Antioquia. p. 77.

Vélez A. (2007). Homo Sapiens, Villegas Editores. p. 120.

Vélez, A., Álvarez W. (2014). Imperfecciones corporales: una visión evolutiva. Medellín. Editorial CES. p. 143.

Vélez A., Vélez J.D., Vélez A.C. (2010). Pensamiento Creativo. Bogotá. Villegas Editores. p. 398.

Vulliemoz, S., Raineteau, O., Jabaudon, D. (2005). Reaching beyond the midline: Why are human brains cross wired? The Lancet Neurology. 4 (2): 87-99.

Ziegler, K. (2013). Pareidolia lingüística.

El Espectador: http://www.elespectador.com/opinion/pareidolialingueistica 